\title{
The Neurosteroidogenic Enzyme $5 \alpha$-Reductase Mediates Psychotic-Like Complications of Sleep Deprivation
}

\author{
Roberto Frau ${ }^{1,2,3}$, Valentina Bini ${ }^{1,2}$, Alessio Soggiu' ${ }^{4}$, Simona Scheggi ${ }^{5,6}$, Alessandra Pardu', Silvia Fanni \\ Paola Roncada ${ }^{4}$, Monica Puligheddu' ${ }^{2,3,7}$, Francesco Marrosu ${ }^{2,3,7}$, Donatella Caruso ${ }^{8}$, Paola Devoto ${ }^{1,2,3}$ and \\ Marco Bortolato*,6 \\ 'Department of Biomedical Sciences, Division of Neuroscience and Clinical Pharmacology, Monserrato, Italy; ${ }^{2}$ Tourette Syndrome Center, \\ Monserrato, Italy; ${ }^{3}$ Sleep Medicine Center; University of Cagliari, Monserrato, Italy; 'L. Spallanzani' Institute, Proteomics Section—Department of \\ Veterinary Sciences and Public Health, University of Milan, Milan, Italy; ${ }^{5}$ Department of Molecular and Developmental Medicine, University of \\ Siena, Siena, Italy; ${ }^{6}$ Department of Pharmacology and Toxicology, College of Pharmacy, University of Utah, Salt Lake City, UT, USA; ${ }^{7}$ Department of \\ Public Health, Section of Neurology, Monserrato, Italy; ${ }^{8}$ Department of Pharmacological and Biomolecular Sciences, Center of Excellence for \\ Neurodegenerative Diseases, University of Milan, Milan, Italy
}

Acute sleep deprivation (SD) can trigger or exacerbate psychosis- and mania-related symptoms; the neurobiological basis of these complications, however, remains elusive. Given the extensive involvement of neuroactive steroids in psychopathology, we hypothesized that the behavioral complications of SD may be contributed by $5 \alpha$-reductase $(5 \alpha R)$, the rate-limiting enzyme in the conversion of progesterone into the neurosteroid allopregnanolone. We first tested whether rats exposed to SD may exhibit brain-regional alterations in $5 \alpha \mathrm{R}$ isoenzymes and neuroactive steroid levels; then, we assessed whether the behavioral and neuroendocrine alterations induced by SD may be differentially modulated by the administration of the $5 \alpha R$ inhibitor finasteride, as well as progesterone and allopregnanolone. SD selectively enhanced $5 \alpha R$ expression and activity, as well as AP levels, in the prefrontal cortex; furthermore, finasteride (I -100 mg/kg, IP) dose-dependently ameliorated PPI deficits, hyperactivity, and risk-taking behaviors, in a fashion akin to the antipsychotic haloperidol and the mood stabilizer lithium carbonate. Finally, PPI deficits were exacerbated by allopregnanolone $(10 \mathrm{mg} / \mathrm{kg}$, IP) and attenuated by progesterone $(30 \mathrm{mg} / \mathrm{kg}, \mathrm{IP})$ in SD-subjected, but not control rats. Collectively, these results provide the first-ever evidence that $5 \alpha \mathrm{R}$ mediates a number of psychosis- and mania-like complications of SD through imbalances in cortical levels of neuroactive steroids.

Neuropsychopharmacology (2017) 42, 2196-2205; doi: I0.1038/npp.2017.I3; published online I5 February 2017

\section{INTRODUCTION}

Alterations of sleep architecture and quality are prominent correlates of symptom severity in a wide array of neuropsychiatric disorders (Benca et al, 1992; Cohrs et al, 2001; Monti and Monti, 2004; Bauer et al, 2006; Parhami et al, 2013); the neurobiological underpinnings of these phenomena, however, remain largely elusive.

One of the best experimental paradigms to study the behavioral complications of hyposomnia is afforded by sleep deprivation (SD). This condition leads to several perceptual and cognitive abnormalities (Killgore, 2010; Daviaux et al, 2014) and has been shown to trigger and/or exacerbate psychotic and manic symptoms, as well as risk-taking behaviors (West et al, 1962; Wehr et al, 1987; Killgore et al, 2006; Kahn-Greene et al, 2007; McKenna et al, 2007);

* Correspondence: Dr M Bortolato, Department of Pharmacology and Toxicology, College of Pharmacy, University of Utah, Skaggs Hall, Room 39|6, 30 S 2000 E, Salt Lake City 84 I I2, UT, USA, Tel: 80। 587 3352, Fax: 801 585 5। II, E-mail: marco.bortolato@utah.edu

Received 12 September 20 I6; revised 18 December 2016; accepted 5 January 2017; accepted article preview online 19 January 2017 accordingly, SD-subjected rats have been shown to exhibit a broad array of manic-like behavioral manifestations (Gessa et al, 1995). Along these lines, we and others have shown that sleep-deprived rats and humans develop deficits in the prepulse inhibition (PPI) of the acoustic startle reflex (Frau et al, 2008; Petrovsky et al, 2014), a well-characterized crossspecies index for the measurement of sensorimotor gating. PPI deficits are observed in schizophrenia and mania (Braff et al, 2001; Perry et al, 2001), underscoring the hightranslational value of this paradigm in the study of SDinduced behavioral complications. In line with this premise, we found that the PPI deficits caused by SD are reversed by antipsychotic drugs, but not by either the antidepressant citalopram or the anxiolytic diazepam (Frau et al, 2008).

Ample evidence has shown that neuroactive steroids have broad psychopathological implications (Dubrovsky, 2005) and may be involved in the pathophysiology of schizophrenia and bipolar disorder (Marx et al, 2006). Building on these premises, we recently studied the psychopathological implications of the enzymes $5 \alpha$-reductase ( $5 \alpha \mathrm{R})$ type 1 and 2 , which catalyze the rate-limiting step in the conversion of progesterone (PROG) and testosterone into the 
neurosteroids $5 \alpha$-dihydroprogesterone (DHP) and $5 \alpha$-dihydrotestosterone (DHT). These compounds are further converted by $3 \alpha$-hydroxysteroid oxidoreductase ( $3 \alpha$-HSOR) into the potent neurosteroids $3 \alpha, 5 \alpha$-tetrahydroprogesterone (allopregnanolone; AP) and $3 \alpha$ - androstanediol (Paba et al, 2011). Systemic administrations of the $5 \alpha \mathrm{R}$ inhibitor finasteride (FIN) countered PPI deficits in a fashion akin to antipsychotics (Bortolato et al, 2008; Frau et al, 2015). Notably, these effects were replicated by FIN infusions into the nucleus accumbens (NAc) and prefrontal cortex (PFC) (Devoto et al, 2012). In line with these ideas, preliminary evidence has documented that FIN may have therapeutic potential for schizophrenia and other neuropsychiatric disorders (Koethe et al, 2008; Muroni et al, 2011; Paba et al, 2011; Bortolato et al, 2012).

This background led us to hypothesize that some of the behavioral complications of SD, including PPI deficits, may be mediated by corticolimbic alterations in $5 \alpha \mathrm{R}$. To test this possibility, we measured the impact of SD on the expression and function of $5 \alpha \mathrm{R}$ in corticolimbic regions and assessed the effects of FIN on PPI deficits and other psychosis- and mania-related behavioral consequences of SD.

\section{MATERIALS AND METHODS}

\section{Animals}

We used adult male Sprague-Dawley rats (Harlan, S. Pietro al Natisone, Italy) weighing between 280 and 320 g. Animals were housed four per cage, with ad libitum access to food and water and maintained on a 12/12-h light/dark cycle (lights on at $19 \mathrm{~h}$ ). Rats were gently handled daily for three days before experimental manipulations. All experimental procedures were in compliance with the National Institute of Health guidelines and approved by the local Institutional Animal Use Committees. All possible efforts were made to minimize animal pain and discomfort and to reduce the number of experimental subjects.

\section{Drugs}

FIN, lithium carbonate, indomethacin, DHT (Sigma-Aldrich, St Louis, MO), PROG, and AP (Tocris Bioscience, Bristol, UK) (Sigma-Aldrich) were suspended in 5\% Tween 80, diluted with $0.9 \%$ saline, and administered by IP injection in a volume of $2 \mathrm{ml} / \mathrm{kg}$. Haloperidol (Sigma-Aldrich) was dissolved in $10 \%$ acetic acid buffered with $\mathrm{NaOH}$ and diluted with saline. FIN, haloperidol and lithium carbonate were administered 40 min before behavioral testing; conversely, AP, PROG and DHT were injected $15 \mathrm{~min}$ before testing.

\section{SD}

Throughout the study, SD was produced using the smallplatform method (Frau et al, 2008), a well-validated experimental paradigm that has been shown to produce near-complete REM sleep reduction and a marked reduction in overall sleep in rodents (Grahnstedt and Ursin, 1985; Machado et al, 2006). Non-sleep deprived (NSD) control rats were placed in the experimental room used for SD procedures with the same temperature and humidity, but kept individually in their home cage, after removal of cage mates. Our prior studies showed that these animals exhibited the same behavioral phenotypes as those of rats kept on large platforms (Frau et al, 2008). The duration of SD was kept at $72 \mathrm{~h}$, based on our prior evidence that this timing is necessary to produce marked and stable PPI deficits in rats (Frau et al, 2008), as well as other mania-related behavioral responses (Gessa et al, 1995). Both SD-subjected and NSD rats had free access to food and water throughout the procedure. The following sections provide a brief description of the methods for behavioral and neurochemical analyses. Additional details are described in Supplementary Information.

\section{Behavioral Analyses}

Immediately following SD, a phenotypic battery was conducted to examine sleep-deprived behavioral sequelae. Startle reflex and PPI were tested in a Plexiglas cylinder mounted on a piezoelectric accelerometric platform (Med Associates, St Albans, VT, USA) as previously detailed (Bortolato et al, 2004). Locomotor activity was measured during the last $20 \mathrm{~min}$ of a $30 \mathrm{~min}$ session in Omnitech Digiscan cages (Columbus, $\mathrm{OH}$, USA) as indicated (Bortolato et al, 2008). Risk propensity was evaluated using a variant of the wire-beam bridge task that was modified for rats, as detailed elsewhere (Bortolato et al, 2009a). Object exploration and social interactions were assessed for 5 and $10 \mathrm{~min}$, respectively, with variants of the protocols described elsewhere (Bortolato et al, 2009a, b).

\section{Neurochemical Analyses}

Immediately following behavioral testing, animals were killed, brain regions were harvested, snap-frozen and stored at $-80^{\circ} \mathrm{C}$ until processed. $5 \alpha \mathrm{R} 1,5 \alpha \mathrm{R} 2$ and $3 \alpha$-HSOR protein levels were examined by western blot as previously reported (Bortolato et al, 2011). Steroid levels were measured using liquid chromatography-tandem mass spectrometry (LC-MS/ MS), as described elsewhere (Caruso et al, 2008). Analyses targeted the following steroids: pregnenolone, PROG, DHP, AP, DHEA, testosterone DHT and $3 \alpha, 5 \alpha$-androstanediol. Given the low size of the NAc, analyses were performed on a broader area of the brain that included the ventral and mediodorsal striatum, in order to achieve a critical content of neurosteroids that may be detected by LC-MS/MS analysis.

\section{Statistical Analyses}

Normality and homogeneity of variance of data distribution were verified by using the Kolmogorov-Smirnov and Bartlett's tests. Statistical analyses were performed with one-way or multiway ANOVAs or linear regression and ANCOVA, as appropriate. Post hoc comparisons were performed by Tukey's test. Non-parametric comparisons were performed with Mann-Whitney tests. The significance threshold was set at 0.05 . 

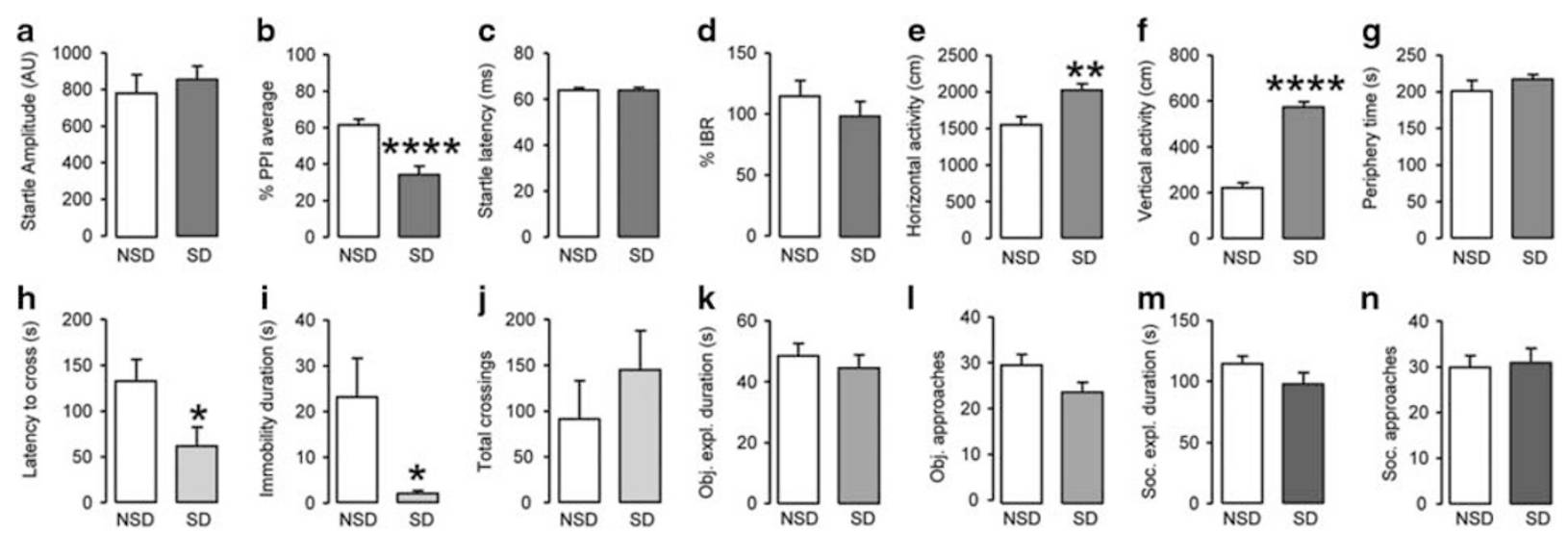

Figure I Sleep deprivation (SD) induces behavioral phenotypes related to manic and psychotic alterations. In comparison with non-sleep deprived (NSD) controls, SD-subjected rats displayed no significant changes in (a) startle amplitude $[\mathrm{F}(\mathrm{I}, 19)=0.30$, NS], but a marked reduction in (b) prepulse inhibition (PPI) $[F(I, 20)=24.39, P<0.000$ I $]$. Conversely, no differences were found in either (c) startle latency or (d) startle habituation (tested as interblock ratio; IBR). The analysis of locomotor activity $(\mathrm{e}-\mathrm{g})$ revealed that SD led to increased $(\mathrm{e})$ horizontal $[F(I, \mid 3)=\mid I .0 I, P<0.0 I]$ and $(f)$ vertical activity $[F(I, \mid 3)=\mid 20.18$, $P<0.000 \mathrm{I}$ ], but did not affect the duration of time spent in $(\mathrm{g})$ the peripheral zone of the arena. In the wire-beam bridge experiment (h-j), SD-subjected rats exhibited a significant decrease in (i) latency to cross the bridge $[F(I, I 3)=5.08, P<0.05]$ and (j) immobility duration $[F(I, I 3)=7.02, P<0.05]$, but did not affect $(k)$ the total distance traveled on the bridge. Notably, SD did not affect either total duration or frequency of exploratory activity directed towards either ( $k$ and $I)$ novel objects or $(m$ and $n$ ) social counterparts. Values represent mean \pm SEM for each group $(n=7-I I)$. * $P<0.05$; $* * P<0.0 I$; ***** $P<0.000 I$, compared to NSD group.

\section{RESULTS}

\section{SD Results in Psychosis- and Mania-Related Behavioral Alterations}

We first confirmed that $72 \mathrm{~h}$ of SD produced robust PPI deficits (Frau et al, 2008) (Figure 1b), but no alterations in startle amplitude (Figure 1a), startle latency (Figure 1c) or startle habituation, as tested by an inter-block ratio (IBR) index (Figure 1d). We then assessed whether the information-processing alterations in rats subjected to this SD regimen also displayed other behavioral changes related to psychosis and mania endophenotypes. In particular, we verified that $\mathrm{SD}$-subjected rats exhibited significant enhancements in horizontal (Figure 1e) and vertical (Figure 1f) activity, but did not exhibit any alterations in the tendency to travel in the periphery of an open arena (Figure 1g), a wellestablished index of anxiety-like behavior in rats.

We then hypothesized that the hyperlocomotion in SDsubjected rats may reflect disinhibition, a core behavioral domain of mania; to test this possibility, we verified the impact of SD on the proclivity to cross a suspended wirebeam bridge task (Bortolato et al, 2009a). In line with clinical evidence (Killgore et al, 2006; McKenna et al, 2007; Womack et al, 2013), SD impaired risk assessment, as signified by a reduced the latency to cross the bridge (Figure $1 \mathrm{~h}$ ) and lower immobility duration (Figure 1i), but not overall distance traveled (Figure $1 \mathrm{j}$ ) on the bridge. Conversely, sleep-deprived rats did not exhibit significant changes in their exploration of either novel objects (Figure $1 \mathrm{k}$ and $\mathrm{l}$ ) or social counterparts (Figure $1 \mathrm{~m}$ and $\mathrm{n}$ ), indicating that the behavioral effects of SD were only specific to select domains of response inhibition.

\section{SD-Induced PPI Alterations are Correlated with Increased Cortico-Accumbal Levels of $5 \alpha \mathrm{R}$ Types 1 and 2}

To test whether these behavioral complications of SD were underpinned by changes in corticolimbic $5 \alpha$ R expression, we first measured the levels of the two main $5 \alpha \mathrm{R}$ isoenzymes (1 and 2) (Paba et al, 2011) in PFC, NAc, hippocampus and amygdala of SD-subjected rats. SD produced significant enhancements in $5 \alpha \mathrm{R} 1$ in the PFC and NAc (Ps<0.05) (Figure 2a and b), but not in the hippocampus or amygdala (Figure $2 \mathrm{c}$ and d). Notably, mean \%PPI levels were negatively correlated with the content of $5 \alpha \mathrm{R} 1$ in the NAc $\left(R^{2}=0.44\right.$; $P<0.05$; ANCOVA), but not in any of the other brain areas (Figure 2e-h). Furthermore, SD-subjected rats showed a significant enhancement of $5 \alpha \mathrm{R} 2$ in the PFC $(P<0.05)$, but not in any of the other areas (Figure $2 \mathrm{i}-1$ ). A robust negative correlation was found between average \%PPI levels and $5 \alpha \mathrm{R} 2$ levels in the PFC $\left(R^{2}=0.66 ; \quad P=0.001 ;\right.$ ANCOVA $)$ (Figure $2 \mathrm{~m}$ ), but not in any of the other structures (Figure $2 n-p)$. No significant correlations were found between startle amplitudes and $5 \alpha \mathrm{R}$ levels in any brain area. In contrast with $5 \alpha \mathrm{R}, \mathrm{SD}$ failed to affect the expression of $3 \alpha-\mathrm{HSOR}$ in either the PFC or NAcc. (Supplementary Figure S1A and B).

\section{SD Results in Enhanced AP Levels in the PFC, But Not Striatum}

To verify whether the changes in $5 \alpha \mathrm{R}$ expression were associated with alterations in brain-regional profiles of neuroactive steroids, we measured the levels of pregnenolone, PROG, DHP, AP (see Figure 3a for a schematization of their metabolic pathway), DHEA, testosterone, DHT and $3 \alpha, 5 \alpha$-androstanediol in the PFC and striatum. Our results revealed that, in the PFC, 72-h SD resulted in a selective, significant increase in the levels of AP, but none of the other steroids (Figure 3b-d; Supplementary Table S1). A significant increase was also found in AP/PROG ratio in the PFC (Figure $3 \mathrm{~g}$ ). No differences, however, were found in the PROG/PREG ratio (Figure 3f). In contrast with the data in the PFC, no significant differences in neurosteroid levels or their ratios were detected in the striatum (including caudateputamen and NAc) (Figure $3 \mathrm{~h}-\mathrm{m}$ and Supplementary 
$5 a \mathrm{R} 1$
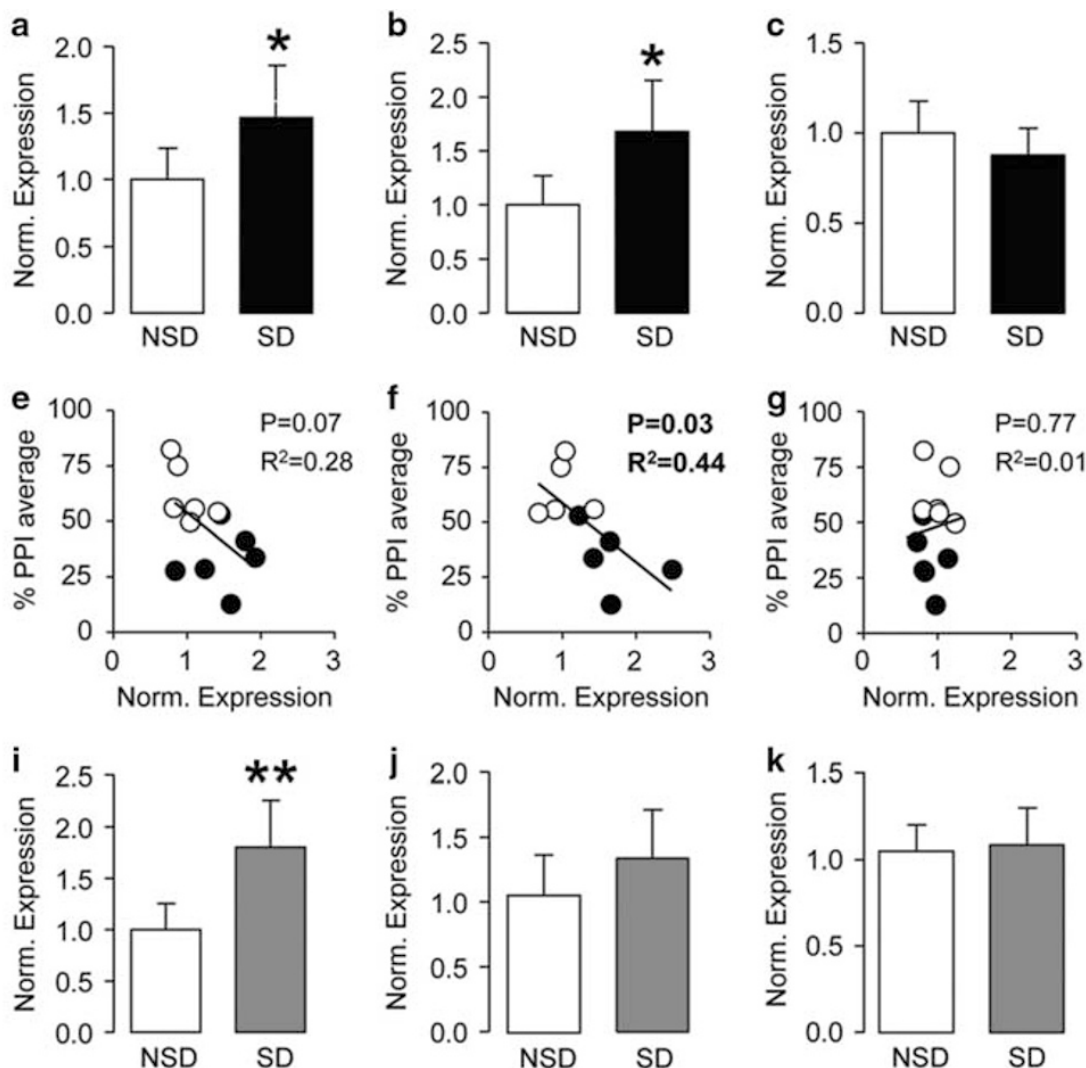

$5 \alpha R 2$
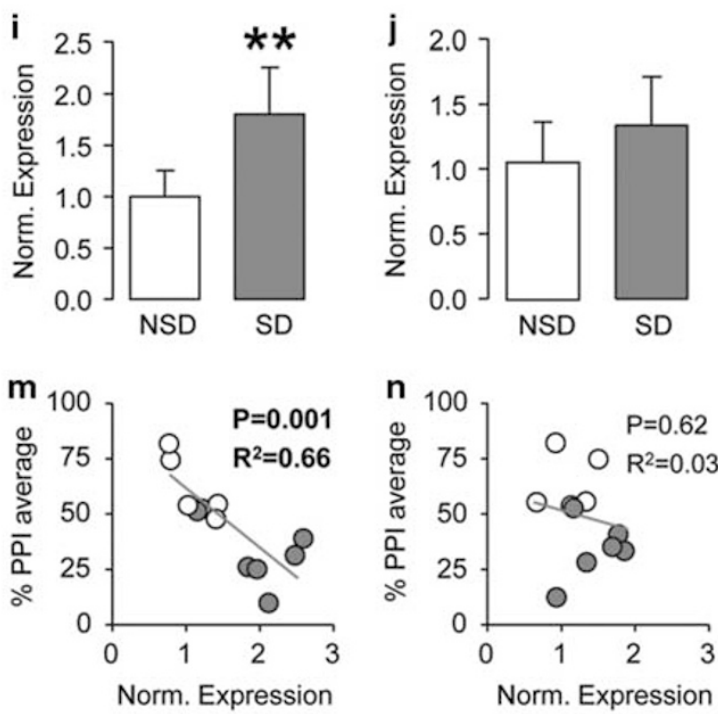

Prefrontal cortex

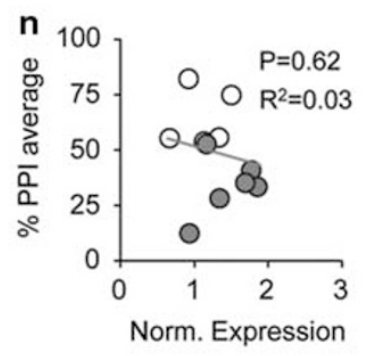

N. Accumbens
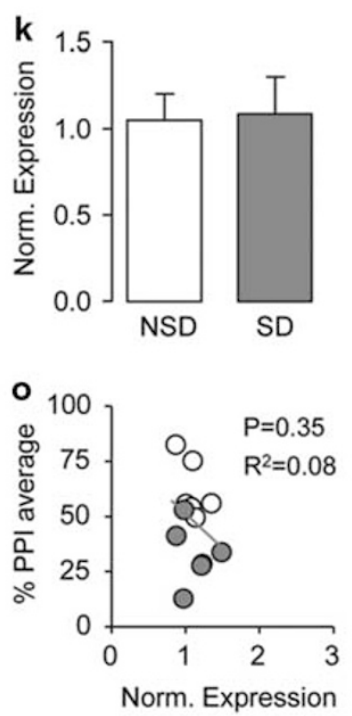

Hippocampus
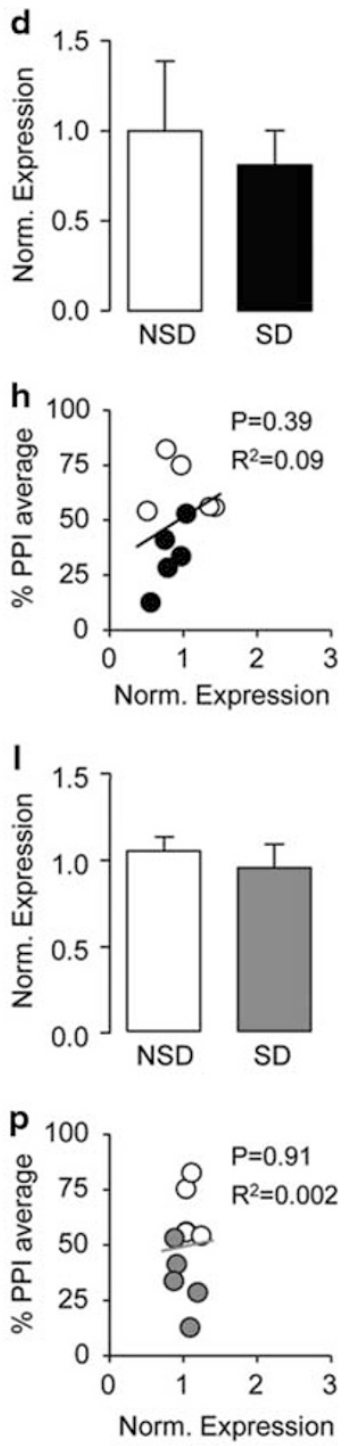

Amygdala

Figure 2 Sleep deprivation (SD) increases protein expressions of both $5 \alpha$-reductase isoforms $(5 \alpha R I$ and $5 \alpha R 2)$ in different brain regions. SD-subjected rats exhibited increased $5 \alpha R I$ expression in (a) the prefrontal cortex $[F(I, I 0)=6.24, P<0.05]$ and (b) nucleus accumbens $[F(I, 8)=7.59, P<0.05]$, but not in $(c)$ hippocampus or (d) amygdala. PPI average levels were negatively correlated with $5 \alpha R I$ in the nucleus accumbens ( $f$ ), but not in any other region (e, g, and $h$ ). SD led to a selective increase of $5 \alpha R 2$ expression in (i) the PFC $[F(I, I 0)=\mid 4.39, P<0.0 I]$, but not in any other brain areas $(j-I)$. Furthermore, the expression of $5 \alpha R 2$ in the PFC $(m)$, but not in any other region $(n-p)$ was negatively correlated with PPI levels. Bars represent means \pm SEM for each group $(n=5-6)$. $* P<0.05$; *P $<0.0$ I, compared to non-sleep deprived (NSD) rats.

Table S1). The levels of DHT and $3 \alpha$-diol were consistently below detection levels in either region.

\section{FIN Reverses Behavioral and Neuroendocrine Effects of SD}

To ascertain whether the behavioral impairments induced by $\mathrm{SD}$ were underpinned by the enhancement in $5 \alpha \mathrm{R}$ and AP levels, we tested the effects of the $5 \alpha \mathrm{R}$ inhibitor finasteride (FIN, $10-100 \mathrm{mg} / \mathrm{kg}$, IP) on the behavioral changes induced by $\mathrm{SD}$, in comparison with the benchmark mood stabilizer lithium carbonate $(50 \mathrm{mg} / \mathrm{kg}$, IP) and the antipsychotic haloperidol $(0.1 \mathrm{mg} / \mathrm{kg}$, IP) (Figure $4 \mathrm{a}-\mathrm{f})$. As expected, FIN dose-dependently reduced startle reflex in both NSD and SD rats (Ps $<0.0001$ for 25 and $100 \mathrm{mg} / \mathrm{kg}$ doses) (Figure $4 \mathrm{a}$ ). Similar effects were induced by both haloperidol (Main effect: $P<0.0001$ ) and lithium (Main effect: $P<0.05$ ). Notably, $25 \mathrm{mg} / \mathrm{kg}$ and $100 \mathrm{mg} / \mathrm{kg}$ FIN countered SDinduced PPI deficits ( $\mathrm{Ps}<0.05$ for both doses), in a fashion similar to lithium carbonate $(P<0.05)$ and haloperidol $(P<0.05)$; however, none of the drugs affected PPI in NSD controls (Figure $4 \mathrm{~b}$ ). The effects of FIN on the other behavioral abnormalities were only tested at the dose of $25 \mathrm{mg} / \mathrm{kg}$, given that, in previous studies and pilot experiments, we found that higher doses of this $5 \alpha \mathrm{R}$ inhibitor significantly reduce spontaneous locomotor activity in control Sprague-Dawley rats (Bortolato et al, 2008). In contrast with the effects of FIN, the inhibitor of $3 \alpha$-HSOR 

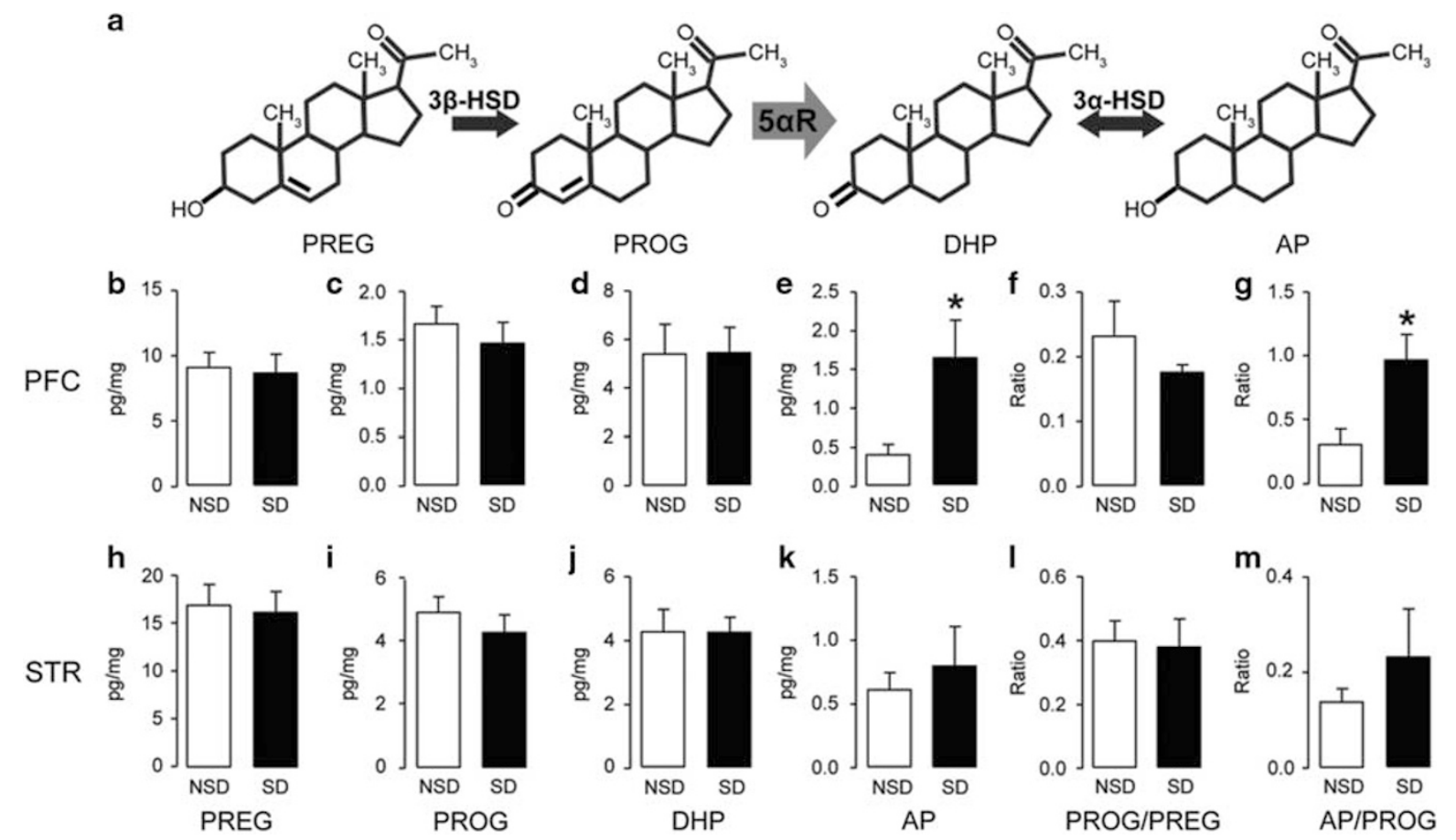

Figure 3 Effects of sleep deprivation (SD) on neurosteroid levels in the prefrontal cortex (PFC) and striatum (STR). (a) shows a schematic representation of the metabolic pathway converting pregnenolone (PREG) into progesterone (PROG), dihydroprogesterone (DHP) and allopregnanolone (AP). SD induced an enhancement in the PFC levels of $A P(e)[F(I, I 8)=5.92 ; P<0.05]$, as well as its ratio with PROG $(g)[F(I, \mid 8)=7.67 ; P<0.05]$. Conversely, no significant

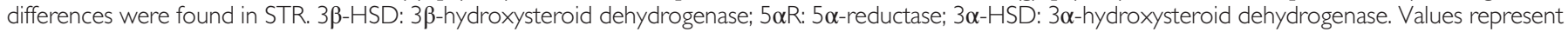
mean \pm SEM for each group $(n=10)$. $* P<0.05$, compared to non-sleep deprived (NSD) rats.

indomethacin $(5 \mathrm{mg} / \mathrm{kg}$, IP) reduced startle magnitude in NSD rats $(P<0.05 v s$ vehicle-treated controls), but not in SD-subjected animals (Supplementary Figure S1C). No effects of this drug were detected on PPI (Supplementary Figure S1D) in either group.

FIN effectively countered SD-induced enhancements in horizontal (Figure 4c; $P<0.001$ ) and vertical (Figure 4d; $P<0.001)$ activity, but had no significant effects on either response in NSD controls; in contrast, lithium reduced horizontal activity in both SD and NSD rats (Main effect: $P<0.001)$, but selectively reduced vertical activity in SD rats $(P<0.01)$. Finally, haloperidol reduced both horizontal and vertical activity irrespective of the experimental condition (Main effects: Ps $<0.0001$ for both analyses).

We next explored whether FIN and lithium could restore the impairment in risk appraisal in the wire-beam bridge task. Given that haloperidol elicited profound locomotor impairments in both SD and NSD rats, this compound was not tested. Pretreatment with FIN or lithium selectively increased the latency to cross the bridge in SD-subjected animals $(P<0.05$ for both; Figure $4 \mathrm{e})$. Conversely, FIN increased the immobility time in the bridge in NSD animals $(P<0.001)$, but did not affect this index in SD-subjected rats (Figure 4f). Furthermore, FIN-treated, SD-subjected rats showed a marked reduction in immobility in comparison with NSD counterparts $(P<0.001)$. Lithium failed to significantly affect immobility (Figure $4 \mathrm{f}$ ).

We then verified whether FIN modified the levels of neuroactive steroids in the PFC and striatum of SD and NSD rats (Supplementary Figure S2). In line with previous results (Frau et al, 2015), FIN produced a significant increase in
PREG and PROG levels $(P s<0.0001$; Supplementary Figure S2A, B, G and H) and reduced the concentrations of DHP $(P \mathrm{~s}<0.01$; Supplementary Figure S2C and I) in both regions, irrespective of the experimental group. AP levels were increased in the PFC of SD-exposed rats, irrespective of FIN treatment $(P<0.01$ Supplementary Figure S3D). This drug, however, selectively opposed the enhancement in the AP/PROG ratio in this region $(P<0.001$; Supplementary Figure S2F), indicating the normalization of $5 \alpha \mathrm{R}$ activity. In the striatum, FIN produced a generalized reduction of AP/ PROG ratio (Main effect: $P<0.05$ ), in both NSD and SD rats (Supplementary Figure S2L).

\section{SD-Induced PPI Deficits are Exacerbated by AP and Attenuated by PROG}

To verify the role of $5 \alpha \mathrm{R}$ substrates and products on the behavioral complications of SD, we tested the effects of AP and PROG. PPI deficits in SD-subjected animals were exacerbated by AP $(P<0.01$; Figure $5 \mathrm{~b})$ and countered by PROG $(P<0.01$; Figure $5 \mathrm{~d})$. These effects, however, were not observed in NSD rats. Furthermore, FIN significantly enhanced PPI in SD-subjected rats treated with AP, but not PROG. Startle analyses revealed that both AP and FIN reduced startle magnitude (Main effects: Ps $<0.01$ ) (Figure 5a), while PROG had no such effect (Figure 5c). In additional studies, we tested the impact of DHT on startle and PPI. DHT increased startle magnitude (Main effect: $P<0.01$; Supplementary Figure S3A) in both SD and NSD rats, but had no effect on PPI (Supplementary Figure S3B). 

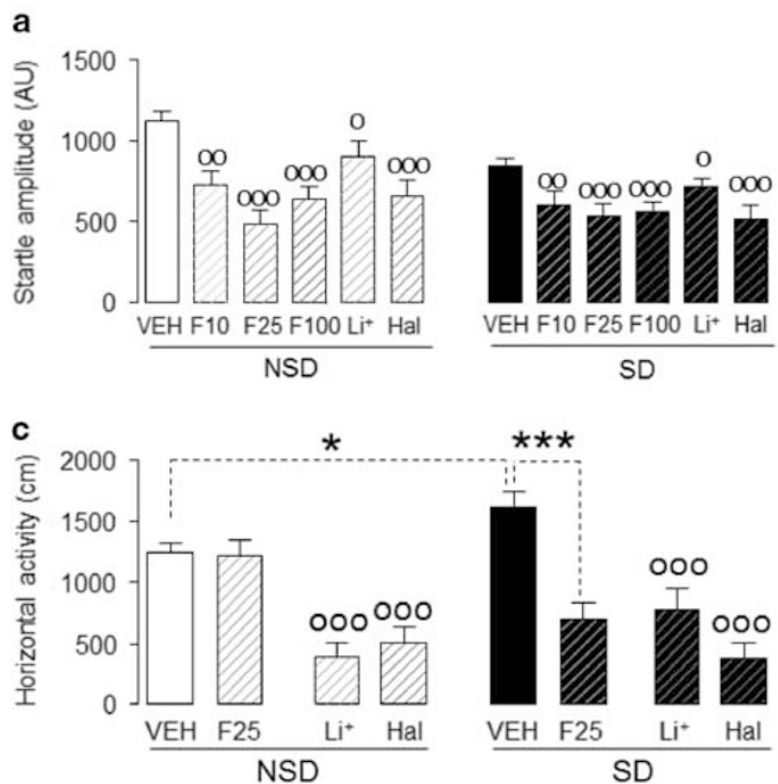

e
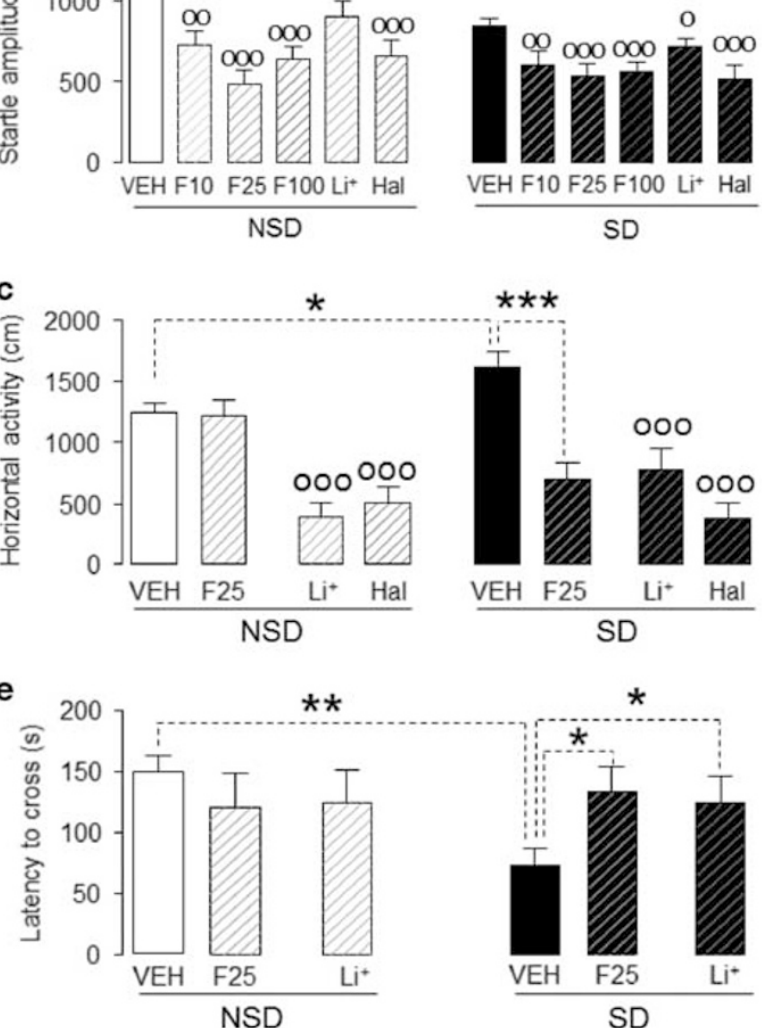

\section{b}
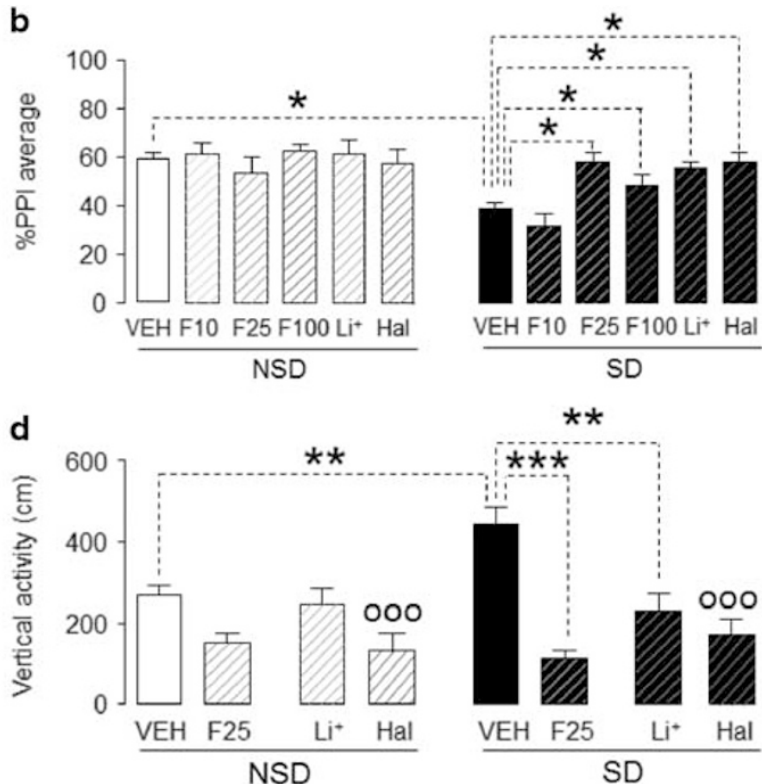

f

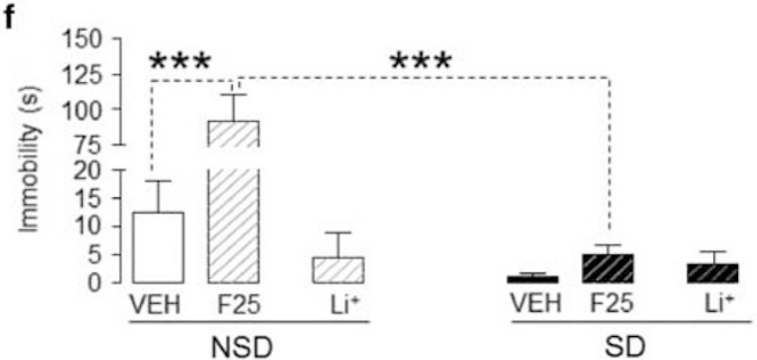

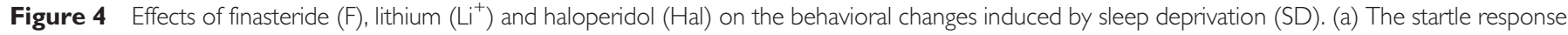

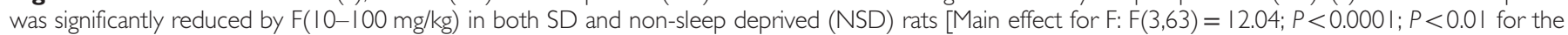

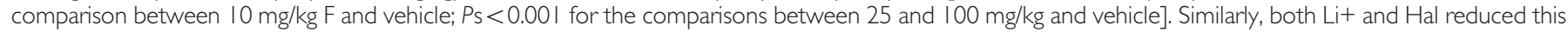

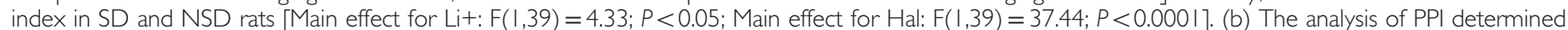

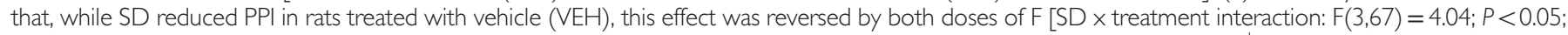

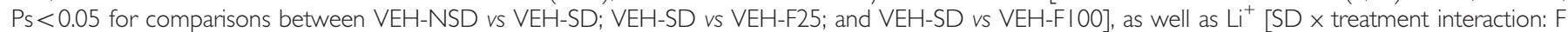

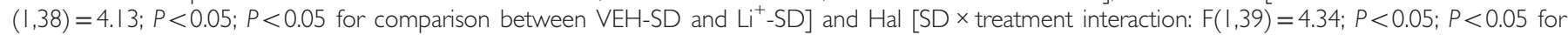

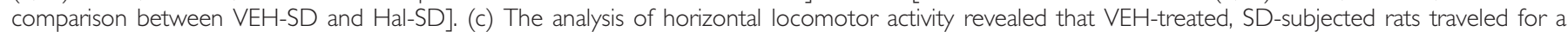

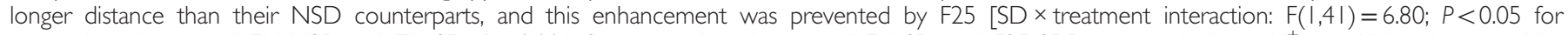

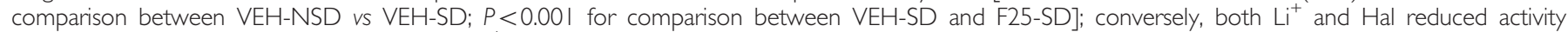

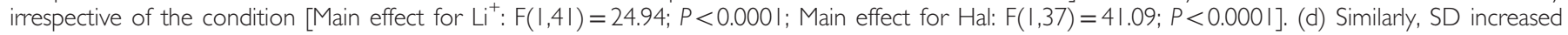

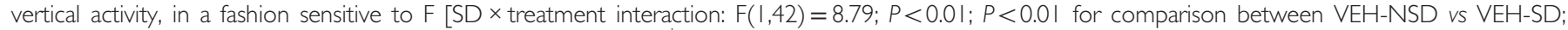

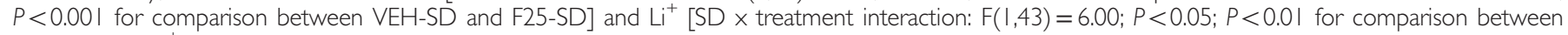

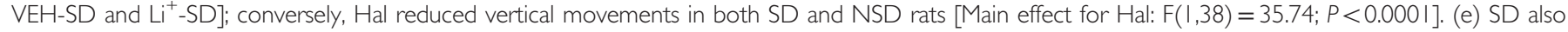

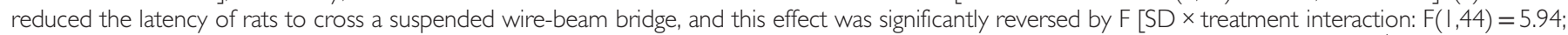

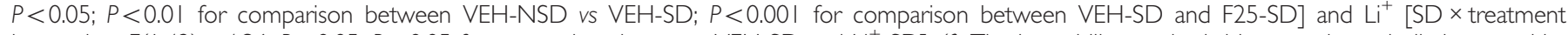

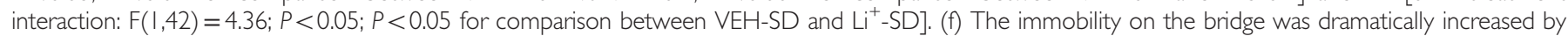

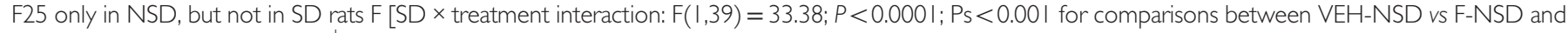

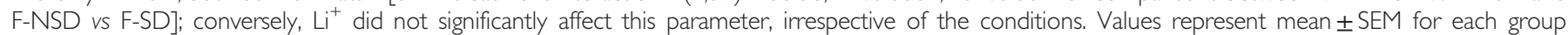

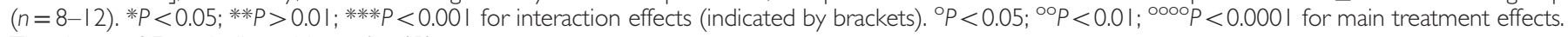
The doses of $F$ are indicated in $\mathrm{mg} / \mathrm{kg}$ (IP).

Finally, we found that AP did not modify locomotor activity in either SD or NSD rats (Supplementary Figure S4).

\section{DISCUSSION}

The results of this study (summarized in Supplementary Table S2) show that SD enhanced the expression of $5 \alpha \mathrm{R} 1$ and 2 , as well as AP synthesis, in the PFC of rats. These neurochemical changes were accompanied by PPI deficits, as well as other behavioral alterations, such as locomotor hyperactivity and increased risk propensity. Notably, these alterations in SD-subjected animals were prevented by the $5 \alpha \mathrm{R}$ inhibitor FIN, in a fashion substantially analogous to the mood stabilizer lithium carbonate and the antipsychotic haloperidol; furthermore, PPI deficits were exacerbated by AP and countered by PROG in SD-subjected rats; conversely, neither neurosteroid had any effect on sensorimotor gating in NSD animals.

Taken together, these findings provide the first indication that $5 \alpha \mathrm{R}$ in the PFC mediates several of the psychotic- and 
a

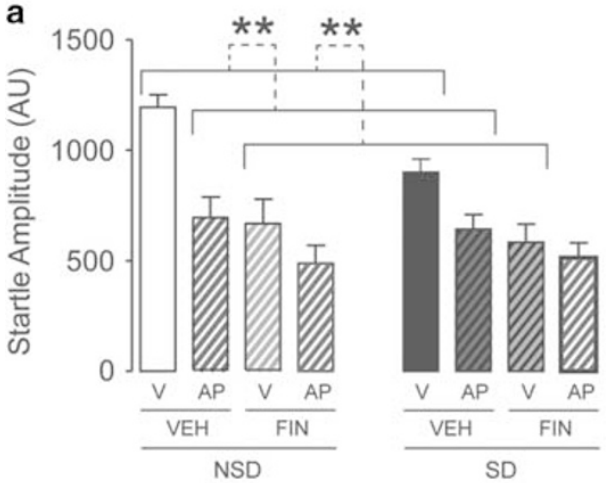

c

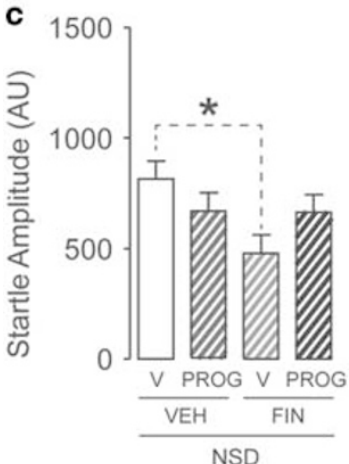

b

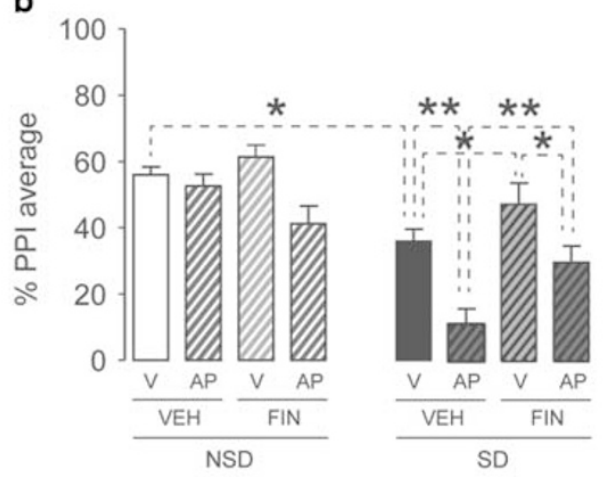

d

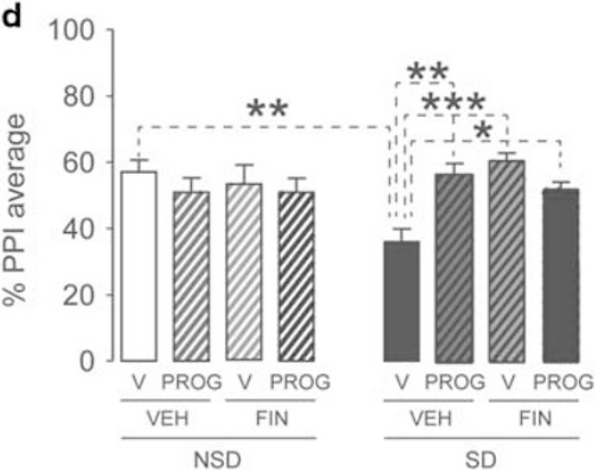

Figure 5 Effects of allopregnanolone (AP, $10 \mathrm{mg} / \mathrm{kg}, \mathrm{IP}$ ) and progesterone (PROG, $30 \mathrm{mg} / \mathrm{kg}$, IP), in combination with finasteride (FIN, $25 \mathrm{mg} / \mathrm{kg}$, IP) on (a and c) startle response and (b and d) prepulse inhibition (PPI) in sleep-deprived (SD) and non-sleep-deprived (NSD) rats. A 2-way interaction between AP and FIN (but not SD conditions) was found in the analysis of startle values (a) $[F(I, 82)=5.45, P<0.05]$. This effect was shown to reflect significant differences between the rats treated with both vehicles and those treated with either AP or FIN (Ps $<0.0$ I for both comparisons). The analysis of PPI values (b) revealed a significant SD $\times$ FIN $\times$ AP interaction $[F(1,82)=4.44 ; P<0.05]$. Post-hoc analyses confirmed that SD reduced $P P I$ in rats $(P<0.05$ for comparison between $S D$ and NSD rats treated with vehicles), and showed that this effect was significantly exacerbated by AP $(P<0.0 \mathrm{I})$, and reduced by FIN $(P<0.05)$. However, the $\mathrm{PPI}$ of SD rats treated with FIN and AP was significantly higher than those treated with vehicle and $A P(P<0.01)$ and lower than those treated with vehicle and FIN $(P<0.05)$. The evaluation of the effects of PROG on startle amplitude $(c)$ revealed a significant $S D \times F I N \times P R O G$ interaction $[F(I, 9 I)=4.74 ; P<0.05]$, which was found to depend on a FIN-induced significant reduction on startle amplitude in NSD rats $(P<0.05)$. Furthermore, the analysis of PPI (d) showed a significant three-way interaction $[F(I, 91)=9.035, P<0.05]$. Post-hoc comparisons confirmed a significant difference between NSD and SD rats, and revealed that both PROG and FIN countered the PPI deficits induced by SD $(P<0.0 \mathrm{I}$ and $P<0.00 \mathrm{I}$, respectively). Values represent mean \pm SEM for each treatment group $(n=8-12)$. V, vehicle of AP/PROG; VEH, vehicle of FIN. *P $<0.05$; **P<0.0I; **** $<0.001$. Brackets indicate significant differences between experimental groups.

manic-like complications of acute SD by facilitating the conversion of PROG into AP. The translational relevance of these results is underscored by the recent demonstration that, in healthy volunteers, SD induces PPI deficits in association with phenotypic changes reminiscent of negative and cognitive symptoms of schizophrenia (Petrovsky et al, 2014). Based on this evidence, SD-induced PPI deficits are currently recognized as a promising surrogate model of psychosis (Petrovsky et al, 2014). It should also be noted that SD has been shown to increase impulsive responses and impair risk assessment (Killgore et al, 2006; McKenna et al, 2007; Venkatraman et al, 2007; Womack et al, 2013), and PPI deficits have been documented in impulse-control disorders and correlated with impulsivity levels (Stojanov et al, 2003; Gee et al, 2015); while future studies are required to verify whether SD-induced PPI deficits may serve as an operational index of impulse-control deficits, previous studies have indicated that this index may predict attentional and executive performance (Bitsios and Giakoumaki, 2005), which is typically defective in impulse-control alterations.

In contrast with $5 \alpha \mathrm{R}, \mathrm{SD}$ did not have any effect on $3 \alpha \mathrm{HSOR}$, the enzyme that converts DHP and DHT into AP and $3 \alpha$-diol, respectively. In agreement with these data, the $3 \alpha \mathrm{HSOR}$ inhibitor indomethacin did not reverse the behavioral effects of SD.

Both AP synthesis and $5 \alpha \mathrm{R}$ levels have been shown to be increased by acute stress in animal models (Purdy et al, 1991; Sánchez et al, 2008), raising the possibility that the stressful component of SD may contribute to the role of $5 \alpha \mathrm{R}$ in the neurobehavioral outcomes of SD. Indeed, the platform method used to induce SD in our study has been shown to elicit a significant stress response (Fadda and Fratta, 1997; Suchecki et al, 1998; Revel et al, 2009). Although future studies on different methods to produce SD in animal models are warranted to ascertain the influence of stress on the observed deficits, it is worth noting that we found that the PPI deficits induced by SD were not observed in rats on large platforms or rats exposed to consistent soaking, indicating that the deficits in sensorimotor gating may be indeed specific to SD (Frau et al, 2008). Furthermore, parsing out the outcomes of SD from those of stress response may be highly problematic, given that SD is inherently stressful and conducive to a robust response of the HPA axis (Vgontzas et al, 1999; McEwen, 2006; Minkel et al, 2014). 
The association of SD-induced phenotypes with alterations in $5 \alpha \mathrm{R}$ and neurosteroids in the PFC may reflect the key role of this region in the regulation of PPI and risk-taking behaviors (Bubser and Koch, 1994; Hazlett et al, 1998; Knoch et al, 2006; St Onge and Floresco, 2010), as well as its high susceptibility to the deleterious effects of SD (Harrison et al, 2000; Durmer and Dinges, 2005; Yan et al, 2011; AcostaPeña et al, 2015). Specifically, our results indicated that PPI levels were negatively correlated with the PFC concentrations of $5 \alpha \mathrm{R} 2$, but not $5 \alpha \mathrm{R} 1$. In adult rats, PFC $5 \alpha \mathrm{R} 2$ is segregated in pyramidal cells (Castelli et al, 2013), the output neurons that project to other cortical areas or subcortical regions. This pattern of expression in rats is strikingly different from that of $5 \alpha \mathrm{R} 1$, which has been shown to be localized also in glial cells (Melcangi et al, 1993). Although, $5 \alpha \mathrm{R} 2$ is significantly less abundant than $5 \alpha \mathrm{R} 1$ in the adult brain (Normington and Russell, 1992), it has a higher affinity for PROG than $5 \alpha \mathrm{R} 1$ (Paba et al, 2011); these premises collectively suggest that $5 \alpha \mathrm{R} 2$ may serve a distinctive role, directly related to the functional control of pyramidal cells in the PFC. Given that AP acts as a positive allosteric modulator of the $\gamma$-aminobutyric acid A (GABA-A) receptor (Belelli and Lambert, 2005), the increased synthesis of this neurosteroid in pyramidal cells may lead to a higher conductance of their GABA-A channels, ultimately resulting in reduced firing patterns of the projections of PFC towards other brain areas. Furthermore, PROG had a protective effect on SD-induced PPI, suggesting that its receptors may be implicated in the complications of SD and in the antipsychotic-like effects of FIN. Overall, these imbalances may be related to changes in signal-to-noise ratio in pyramidal neurons, leading to temporary dysfunctions of PFC activity. While GABA-A and PROG receptors likely contribute to the regulation of PPI in SD-subjected animals, we cannot exclude that these phenomena may also reflect the involvement of other receptors in the $\mathrm{PFC}$ with high affinity for $\mathrm{AP}$ and/or PROG, such as the membrane PROG receptors, PXR, NMDA and $\sigma$ receptors (Cooke et al, 2013, Frye et al, 2014; Vyklicky et al, 2015).

The behavioral changes induced by SD may have been contributed by other regions than PFC. In particular, $5 \alpha \mathrm{R} 1$ expression was significantly increased in the NAc. Due to the small size of this region, we could not assess whether these changes may lead to functional alterations of this enzyme. Pooling the region with the dorsal striatum failed to reveal any significant change; however, this result should be considered with caution, given that NAc represents only a small portion of the overall sampled tissues. Moreover, our previous results showed that the antipsychotic-like actions of FIN on the PPI deficits induced by the dopaminergic nonselective agonist apomorphine were fully replicated by intraNAc infusions (Devoto et al, 2012).

In addition to rescuing the changes in AP/PROG ratio, FIN also produced a number of other changes in neurosteroid profile in the PFC and striatum. In line with previous findings (Frau et al, 2015), this drug increased PREG and, to a lesser extent, PROG levels. While the underpinnings of these effects are unknown, it is possible that this phenomenon may reflect an internal feedback mechanism controlling the activity of key promoters of ex novo neurosteroidogenesis, such as the $18-\mathrm{kDa}$ translocator protein or the steroidogenic acute regulatory (StAR) protein.
On this score, it is worth noting that DHT reduces StAR expression (Houk et al, 2004); thus, a reduction in DHT levels induced by FIN may lead to a major enhancement in neurosteroidogenesis and PREG production. Irrespective of these issues, it is possible that the enhancement in PREG may be instrumental to enable the activity of FIN in restoring hyperactivity in SD-subjected rats. In keeping with this concept, previous reports have shown that PREG may exert antipsychotic-like actions in both patients and animal models (Marx et al, 2009; Wong et al, 2012).

A number of limitations should be acknowledged: first, our studies were only conducted in male rats; given the implication of $5 \alpha$ Rs in the synthesis of sex hormones, it is possible that the phenotypic effects of neurosteroids in SDsubjected rats may be different; second, although our results imply that changes in cortical steroids are conducive to alterations in PPI and other behavioral responses, this thesis should be further supported by injections of neurosteroids and FIN in the PFC. Indeed, it is possible that other regions not included in our analyses may play an important role in the phenotypic effects documented in this study; third, pharmacological treatments with FIN and other agents was generally limited to a relatively narrow dose range; in consideration of the complex dose-response profiles of neurosteroids, we cannot exclude that our analyses may have failed to identify additional effects of the drugs tested; fourth, it is possible that our assessment of the behavioral effects of FIN in SD may be limited by the intrinsic hypolocomotive effects of this drug in NSD controls. These caveats notwithstanding, the present study has provided the first-ever demonstration that the neurosteroidogenic enzyme $5 \alpha \mathrm{R}$ mediates psychosis- and mania-related complications of SD. These findings, as well as emerging evidence on the therapeutic properties of FIN in several conditions exacerbated by $\mathrm{SD}$, may open up to new horizons for the development of neurosteroid-based therapies in psychiatry and as novel tools to offset the negative psychological impact of sleep disturbances. Accordingly, preliminary evidence from our group has shown that $5 \alpha \mathrm{R}$ inhibitors may exert therapeutic effects in a number of disorders characterized by sensorimotor gating deficits and exacerbated by sleep loss, such as schizophrenia, pathological gambling and Tourette syndrome (Koethe et al, 2008; Muroni et al, 2011; Bortolato et al, 2012).

\section{FUNDING AND DISCLOSURE}

The authors declare no conflict of interest.

\section{ACKNOWLEDGMENTS}

MB designed the research, analyzed the data and wrote the manuscript; RF wrote the first draft of the manuscript, performed the behavioral studies, analyzed the data and managed the literature search; VB, AP, and SF performed the behavioral tests; DC performed the neurochemical assays; PR and AS performed the molecular assays; PD, FM, MP, DC, $\mathrm{PR}$ revised the paper. We would like to thank Graziella De Montis and Carla Gambarana for their support in the execution of western-blotting experiments; Pierluigi Saba and Barbara Tuveri for their technical assistance; and Sean 
Godar for his valuable comments on the manuscript and assistance with the figures. This work was partially supported by grants from the National Institute of Health (R01 MH104603; to MB), Tourette Syndrome Association of America (to MB), Italian Ministry of Health grant PE-201102351898 (to MP), Michael J Fox Foundation grant 9969 (to PD), and Regione Autonoma della Sardegna (to PD). None of the institutions had any further role in the decision to submit the paper for publication.

\section{REFERENCES}

Acosta-Peña E, Camacho-Abrego I, Melgarejo-Gutiérrez M, Flores G, Drucker-Colín R, García-García F (2015). Sleep deprivation induces differential morphological changes in the hippocampus and prefrontal cortex in young and old rats. Synapse 69: 15-25.

Bauer M, Grof P, Rasgon N, Bschor T, Glenn T, Whybrow PC (2006). Temporal relation between sleep and mood in patients with bipolar disorder. Bipolar Disord 8: 160-167.

Belelli D, Lambert JJ (2005). Neurosteroids: endogenous regulators of the GABA(A)receptor. Nat Rev Neurosci 6: 565-575.

Benca RM, Obermeyer WH, Thisted RA, Gillin JC (1992). Sleep and psychiatric disorders. A meta-analysis. Arch Gen Psychiatry 49: 651-668.

Bitsios P, Giakoumaki SG (2005). Relationship of prepulse inhibition of the startle reflex to attentional and executive mechanisms in man. Int J Psychophysiol 55: 229-241.

Bortolato M, Cannas A, Solla P, Bini V, Puligheddu M, Marrosu F (2012). Finasteride attenuates pathological gambling in patients with Parkinson disease. J Clin Psychopharmacol 32: 424-425.

Bortolato M, Devoto P, Roncada P, Frau R, Flore G, Saba P et al (2011). Isolation rearing-induced reduction of brain $5 \alpha$-reductase expression: relevance to dopaminergic impairments. Neuropharmacology 60: 1301-1308.

Bortolato M, Frau R, Aru GN, Orrù M, Gessa GL (2004). Baclofen reverses the reduction in prepulse inhibition of the acoustic startle response induced by dizocilpine, but not by apomorphine. Psychopharmacology 171: 322-330.

Bortolato M, Frau R, Orrù M, Bourov Y, Marrosu F, Mereu G et al (2008). Antipsychotic-like properties of 5-alpha-reductase inhibitors. Neuropsychopharmacology 33: 3146-3156.

Bortolato M, Frau R, Piras AP, Luesu W, Bini V, Diaz G et al (2009b). Methamphetamine induces long-term alterations in reactivity to environmental stimuli: correlation with dopaminergic and serotonergic toxicity. Neurotox Res 15: 232-245.

Bortolato M, Godar SC, Davarian S, Chen K, Shih JC (2009a). Behavioral disinhibition and reduced anxiety-like behaviors in monoamine oxidase B-deficient mice. Neuropsychopharmacology 34: 2746-2757.

Braff DL, Geyer MA, Swerdlow NR (2001). Human studies of prepulse inhibition of startle: normal subjects, patient groups, and pharmacological studies. Psychopharmacology 156: 234-258.

Bubser M, Koch M (1994). Prepulse inhibition of the acoustic startle response of rats is reduced by 6-hydroxydopamine lesions of the medial prefrontal cortex. Psychopharmacology 113: 487-492.

Caruso D, Scurati S, Maschi O, De Angelis L, Roglio I, Giatti S et al (2008). Evaluation of neuroactive steroid levels by liquid chromatography-tandem mass spectrometry in central and peripheral nervous system: effect of diabetes. Neurochem Int 52: 560-568.

Castelli MP, Casti A, Casu A, Frau R, Bortolato M, Spiga S et al (2013). Regional distribution of $5 \alpha$-reductase type 2 in the adult rat brain: an immunohistochemical analysis. Psychoneuroendocrinology 38: 281-293.

Cohrs S, Rasch T, Altmeyer S, Kinkelbur J, Kostanecka T, Rothenberger A et al (2001). Decreased sleep quality and increased sleep related movements in patients with Tourette's syndrome. J Neurol Neurosurg Psychiatry 70: 192-197.

Cooke PS, Nanjappa MK, Yang Z, Wang KK (2013). Therapeutic effects of progesterone and its metabolites in traumatic brain injury may involve non-classical signaling mechanisms. Front Neurosci 7: 108.

Daviaux Y, Mignardot JB, Cornu C, Deschamps T (2014). Effects of total sleep deprivation on the perception of action capabilities. Exp Brain Res 232: 2243-2253.

Devoto P, Frau R, Bini V, Pillolla G, Saba P, Flore G et al (2012). Inhibition of $5 \alpha$-reductase in the nucleus accumbens counters sensorimotor gating deficits induced by dopaminergic activation. Psychoneuroendocrinology 37: 1630-1645.

Dubrovsky BO (2005). Steroids, neuroactive steroids and neurosteroids in psychopathology. Prog Neuropsychopharmacol Biol Psychiatry 29: 169-192.

Durmer JS, Dinges DF (2005). Neurocognitive consequences of sleep deprivation. Semin Neurol 25: 117-129.

Fadda P, Fratta W (1997). Stress-induced sleep deprivation modifies corticotropin releasing factor (CRF) levels and CRF binding in rat brain and pituitary. Pharmacol Res 35: 443-446.

Frau R, Abbiati F, Bini V, Casti A, Caruso D, Devoto P et al (2015). Targeting neurosteroid synthesis as a therapy for schizophreniarelated alterations induced by early psychosocial stress. Schizophr Res 168: 640-648.

Frau R, Orrù M, Puligheddu M, Gessa GL, Mereu G, Marrosu F et al (2008). Sleep deprivation disrupts prepulse inhibition of the startle reflex: reversal by antipsychotic drugs. Int J Neuropsychopharmacol 11: 947-955.

Frye CA, Koonce CJ, Walf AA (2014). Novel receptor targets for production and action of allopregnanolone in the central nervous system: a focus on pregnane xenobiotic receptor. Front Cell Neurosci 8: 106.

Gee L, Smith H, De La Cruz P, Campbell J, Fama C, Haller J et al (2015). The Influence of Bilateral Subthalamic Nucleus Deep Brain Stimulation on Impulsivity and Prepulse Inhibition in Parkinson's Disease Patients. Stereotact Funct Neurosurg 93: 265-270.

Gessa GL, Pani L, Fadda P, Fratta W (1995). Sleep deprivation in the rat: an animal model of mania. Eur Neuropsychopharmacol 5 Suppl: 89-93.

Grahnstedt S, Ursin R (1985). Platform sleep deprivation affects deep slow wave sleep in addition to REM sleep. Behav Brain Res 18: $233-239$.

Harrison Y, Horne JA, Rothwell A (2000). Prefrontal neuropsychological effects of sleep deprivation in young adults-a model for healthy aging? Sleep 23: 1067-1073.

Hazlett EA, Buchsbaum MS, Haznedar MM, Singer MB, Germans MK, Schnur DB et al (1998). Prefrontal cortex glucose metabolism and startle eyeblink modification abnormalities in unmedicated schizophrenia patients. Psychophysiology 35: 186-198.

Houk CP, Pearson EJ, Martinelle N, Donahoe PK, Teixeira J (2004). Feedback inhibition of steroidogenic acute regulatory protein expression in vitro and in vivo by androgens. Endocrinology 145 : 1269-1275.

Kahn-Greene ET, Killgore DB, Kamimori GH, Balkin TJ, Killgore WD (2007). The effects of sleep deprivation on symptoms of psychopathology in healthy adults. Sleep Med 8: 215-221.

Killgore WD (2010). Effects of sleep deprivation on cognition. Prog Brain Res 185: 105-129.

Killgore WD, Balkin TJ, Wesensten NJ (2006). Impaired decision making following $49 \mathrm{~h}$ of sleep deprivation. J Sleep Res 15: 7-13.

Knoch D, Gianotti LR, Pascual-Leone A, Treyer V, Regard M, Hohmann $\mathrm{M}$ et al (2006). Disruption of right prefrontal cortex by low-frequency repetitive transcranial magnetic stimulation induces risk-taking behavior. J Neurosci 26: 6469-6472.

Koethe D, Bortolato M, Piomelli D, Leweke FM (2008). Improvement of general symptoms in a chronic psychotic patient treated with finasteride: case report. Pharmacopsychiatry 41: 115-116. 
Machado RB, Suchecki D, Tufik S (2006). Comparison of the sleep pattern throughout a protocol of chronic sleep restriction induced by two methods of paradoxical sleep deprivation. Brain Res Bull 70: 213-220.

Marx CE, Keefe RS, Buchanan RW, Hamer RM, Kilts JD, Bradford DW et al (2009). Proof-of-concept trial with the neurosteroid pregnenolone targeting cognitive and negative symptoms in schizophrenia. Neuropsychopharmacology 34: 1885-1903.

Marx CE, Stevens RD, Shampine LJ, Uzunova V, Trost WT, Butterfield MI et al (2006). Neuroactive steroids are altered in schizophrenia and bipolar disorder: relevance to pathophysiology and therapeutics. Neuropsychopharmacology 31: 1249-1263.

McEwen BS (2006). Sleep deprivation as a neurobiologic and physiologic stressor: Allostasis and allostatic load. Metabolism 55: S20-S23.

McKenna BS, Dickinson DL, Orff HJ, Drummond SP (2007). The effects of one night of sleep deprivation on known-risk and ambiguous-risk decisions. J Sleep Res 16: 245-252.

Melcangi RC, Celotti F, Castano P, Martini L (1993). Differential localization of the 5 alpha-reductase and the 3 alpha-hydroxysteroid dehydrogenase in neuronal and glial cultures. Endocrinology 132: 1252-1259.

Minkel J, Moreta M, Muto J, Htalk O, Jones C, Basner M et al (2014). Sleep deprivation potentiates HPA axis stress reactivity in healthy adults. Health Psychol 33: 1430-1434.

Monti JM, Monti D (2004). Sleep in schizophrenia patients and the effects of antipsychotic drugs. Sleep Med Rev 8: 133-148.

Muroni A, Paba S, Puligheddu M, Marrosu F, Bortolato M (2011). A preliminary study of finasteride in Tourette syndrome. Mov Disord 26: 2146-2147.

Normington K, Russell DW (1992). Tissue distribution and kinetic characteristics of rat steroid 5 alpha-reductase isozymes. Evidence for distinct physiological functions. J Biol Chem 267: 19548-19554.

Paba S, Frau R, Godar SC, Devoto P, Marrosu F, Bortolato M (2011). Steroid $5 \alpha$-reductase as a novel therapeutic target for schizophrenia and other neuropsychiatric disorders. Curr Pharm Des 17: 151-167.

Parhami I, Siani A, Rosenthal RJ, Fong TW (2013). Pathological gambling, problem gambling and sleep complaints: an analysis of the National Comorbidity Survey: Replication (NCS-R). J Gambl Stud 29: 241-253.

Paxinos G, Watson C (2005). The Rat brain in stereotaxic coordinates, 5th edn. Elsevier Academic Press: San Diego, CA.

Perry W, Minassian A, Feifel D, Braff DL (2001). Sensorimotor gating deficits in bipolar disorder patients with acute psychotic mania. Biol Psychiatry 50: 418-424.
Petrovsky N, Ettinger U, Hill A, Frenzel L, Meyhöfer I, Wagner M et al (2014). Sleep deprivation disrupts prepulse inhibition and induces psychosis-like symptoms in healthy humans. J Neurosci 34: 9134-9140.

Purdy RH, Morrow AL, Moore PH Jr, Paul SM (1991). Stressinduced elevations of gamma-aminobutyric acid type A receptoractive steroids in the rat brain. Proc Natl Acad Sci USA 88: 4553-4557.

Revel FG, Gottowik J, Gatti S, Wettstein JG, Moreau JL (2009). Rodent models of insomnia: a review of experimental procedures that induce sleep disturbances. Neurosci Biobehav Rev 33: 874-899.

Sánchez P, Torres JM, Gavete P, Ortega E (2008). Effects of swim stress on mRNA and protein levels of steroid 5alpha-reductase isozymes in prefrontal cortex of adult male rats. Neurochem Int 52: 426-431.

St Onge JR, Floresco SB (2010). Prefrontal cortical contribution to risk-based decision making. Cereb Cortex 20: 1816-1828.

Stojanov W, Karayanidis F, Johnston P, Bailey A, Carr V, Schall U (2003). Disrupted sensory gating in pathological gambling. Biol Psychiatry 54: 474-484.

Suchecki D, Lobo LL, Hipólide DC, Tufik S (1998). Increased ACTH and corticosterone secretion induced by different methods of paradoxical sleep deprivation. J Sleep Res 7: 276-281.

Venkatraman V, Chuah YM, Huettel SA, Chee MW (2007). Sleep deprivation elevates expectation of gains and attenuates response to losses following risky decisions. Sleep 30: 603-609.

Vgontzas AN, Mastorakos G, Bixler EO, Kales A, Gold PW, Chrousos GP (1999). Sleep deprivation effects on the activity of the hypothalamic-pituitary-adrenal and growth axes: potential clinical implications. Clin Endocrinol 51: 205-215.

Vyklicky V, Krausova B, Cerny J, Balik A, Zapotocky M, Novotny $\mathrm{M}$ et al (2015). Block of NMDA receptor channels by endogenous neurosteroids: implications for the agonist induced conformational states of the channel vestibule. Sci Rep 5: 10935.

Wehr TA, Sack DA, Rosenthal NE (1987). Sleep reduction as a final common pathway in the genesis of mania. Am J Psychiatry 144: 201-204.

West LJ, Janszen HH, Lester BK, Cornelisoon FS Jr (1962). The psychosis of sleep deprivation. Ann N Y Acad Sci 96: 66-70.

Womack SD, Hook JN, Reyna SH, Ramos M (2013). Sleep loss and risk-taking behavior: a review of the literature. Behav Sleep Med 11: 343-359.

Wong P, Chang CC, Marx CE, Caron MG, Wetsel WC, Zhang X (2012). Pregnenolone rescues schizophrenia-like behavior in dopamine transporter knockout mice. PLoS One 7: e51455.

Yan J, Li JC, Xie ML, Zhang D, Qi AP, Hu B et al (2011). Short-term sleep deprivation increases intrinsic excitability of prefrontal cortical neurons. Brain Res 1401: 52-58.

Supplementary Information accompanies the paper on the Neuropsychopharmacology website (http://www.nature.com/npp) 